\title{
Contacts between domestic livestock and wildlife at the Kruger National Park Interface of the Republic of South Africa
}

\section{Dipa P. Brahmbhatt ${ }^{\mathrm{a}}$, Geoffrey T. Fosgate ${ }^{\mathrm{b}}$, Edwin Dyason ${ }^{\mathrm{c}}$, Christine M. Budke ${ }^{\mathrm{a}^{*}}$ Bruce Gummow $^{\text {b,d }}$, Ferran Jori ${ }^{\mathrm{b}, \mathrm{e}}$, Michael P. Ward ${ }^{\mathrm{f}}$, R Srinivasan ${ }^{\mathrm{g}}$}

${ }^{a}$ Department of Veterinary Integrative Biosciences, Texas A\&M University College of Veterinary Medicine and Biomedical Sciences, College Station, TX, 77843-4458, USA

${ }^{b}$ Department of Production Animal Studies, Faculty of Veterinary Science, University of Pretoria, Onderstepoort, South Africa ${ }^{c}$ Limpopo Department of Agriculture, Polokwane, South Africa

${ }^{d}$ School of Veterinary and Biomedical Sciences, James Cook University, Townsville 4811, Queensland, Australia ${ }^{e}$ French Agricultural Research Center for International Development,(CIRAD), Animal Integrated Risk Management Unit (AGIRs), Mammal Research Institute, Department of Zoology, 0002 University of Pretoria, South Africa

${ }^{f}$ Faculty of Veterinary Science, The University of Sydney, 425 Werombi Road, Camden, NSW 2570, Australia ${ }^{g}$ Ecosystem Science and Management, Texas A\&M University, College Station, Texas, 77843, USA

* Corresponding author. Tel.: +1 979 458-2154; fax: +1 9798478981

E-mail address: $\underline{\text { CBudke@ @ cvm.tamu.edu (C.M. Budke) }}$ 


\begin{abstract}
One of the most important transboundary animal diseases (TADs) in the southern African region is foot-and-mouth disease (FMD). In this region, a pathway for spread of FMD virus is contacts between cattle and certain species of wildlife. The objective of this study was to evaluate contacts between cattle and wildlife in the Kruger National Park (KNP) and the adjacent Limpopo province for the time periods October 2006 to March 2007 and April to September 2007. In this study, 87 livestock owners and 57 KNP field rangers were interviewed. Fifteen (17\%) livestock owners reported contacts between wildlife and cattle. More livestock owners reported observing contacts between cattle and all wildlife species during October-March than April-September $(\mathrm{p}=0.012)$. However, no difference was found between these periods for contacts between cattle and individual wildlife species. A total of eighteen (32\%) field rangers reported contacts between cattle and wildlife. The most common species-specific contacts were between cattle and buffalo (63/year), cattle and impala (17/year) and cattle and lion (10/year). There were no significant differences in rangers reporting observed contacts between cattle and wildlife during October-March versus April-September or between rangers reporting observed contacts outside versus within the KNP. Overall, there was no evidence of higher contact rates between cattle and wildlife in the study area during October-March compared to April-September. Contact data collected in this study can be used to better understand the transmission of FMD virus in this region.
\end{abstract}

Keywords: contacts, foot-and-mouth disease, wildlife-cattle interface, Kruger National Park 


\section{Introduction}

Transboundary animal diseases (TADs) are diseases "that are of significant economic, trade and/or food security importance for a considerable number of countries; which can easily spread to other countries and reach epidemic proportions; and where control/management, including exclusion, requires co-operation between several countries" (EMPRES, 1997). Contact between domestic livestock and wildlife is important for transmission of TADs in certain geographic locations, such as the Kruger National Park (KNP) and its adjacent provinces. An important TAD in this part of the Republic of South Africa (RSA) is foot-and-mouth disease (FMD), a highly contagious viral disease of cloven-hoofed animals.

Except for the KNP and adjacent FMD control zones, the RSA is considered free of FMD by the World Organization for Animal Health (OIE) (Bastos et al., 2000). The National Veterinary Services (NVS) of the RSA and the Provincial Veterinary Services (PVS) are responsible for FMD control through inspection, vaccination and issuing movement control permits for the KNP and adjacent provinces. Wildlife species in the KNP that are known to be infected by FMD include African buffalo (Synercus caffer) and impala (Aepyceros melampus) (Thomson, 1994; Keet et al., 1996; Vosloo et al., 2006). African buffalo populations are a reservoir for FMD virus (FMDV) (Hedger, 1972; Condy et al., 1985; Thomson et al., 2003; Hargreaves et al., 2004). Infection in African buffalo is sub-clinical and usually occurs in buffalo calves as maternal antibodies wane (Hedger, 1972; Thomson et al., 1992). Approximately $60 \%$ of infected African buffaloes become carriers and have been reported to be latently infected for up to 24 years (Condy et al., 1985). Impala are highly susceptible to FMDV infection (Keet et al., 1996; Vosloo et al., 2009). Outbreaks of FMD in impala have been shown 
to occur most frequently just before or during the winter in the RSA, which coincides with when buffalo calves have lost their maternal antibodies (Bastos et al., 2000; Vosloo et al., 2006).

Five outbreaks of FMD in domestic livestock within the RSA were reported from 2000 2006 (OIE, 1992-2006) and contact with infected wildlife was suspected in four of these outbreaks (Vosloo et al., 2002). The first two outbreaks were reported in Mpumalanga (serotype SAT 1) and KwaZulu-Natal (serotype O) provinces. Three outbreaks of SAT serotypes were then reported from Limpopo province in 2001 (SAT 2), 2004 (SAT 2) and 2006 (SAT 3). Except for the outbreak involving the O serotype, all other livestock outbreaks are believed to have been due to fence damage that allowed contact with buffalo (Vosloo et al., 2002; Vosloo et al., 2006).

Disease transmission from wildlife to domestic livestock is determined by the type and frequency of contact, environmental factors and pathogen strain. The most common method of FMDV spread is via direct contact, either by mechanical transfer of the virus or inhalation Therefore, the objective of this study was to estimate livestock owner and field ranger reported contacts between cattle and wildlife in the KNP and neighboring Limpopo province during the periods October 2006 to March 2007 and April to September 2007.

\section{Materials and Methods}

\subsection{Study location}

The study location included 11 of 13 sections of the KNP that form the park's western boundary and the buffer zone with FMD vaccination in neighboring Limpopo province, which together make up part of the KNP Interface (KNPI). The buffer zone with FMD vaccination consists of a 10 kilometer wide area where animals are vaccinated against FMDV. Two of the 
$13 \mathrm{KNP}$ sections were not included in this study because they do not have a fence. In addition to the $11 \mathrm{KNP}$ sections, one private and one provincial reserve adjacent to KNP were also included in the study.

\subsection{Study population}

The study population consisted of livestock owners residing on communal lands in Limpopo province and field rangers working within the KNP. The approximately 2,322 livestock owners residing in the study area are the first line of alert and response for incidents between wildlife and domestic livestock in the KNPI. The study area within the buffer zone with vaccination in Limpopo province has 31 dip tanks where livestock owners bring their animals every week for dipping against ticks and for clinical inspection for FMD. Dip tanks are managed by PVS government veterinarians and veterinary technicians. All dip tanks were included in the

study, with the goal of sampling 3 livestock owners from each dip tank. Only 3 livestock owners were sampled because owners spend approximately an hour at the dip tank before taking their cattle to graze, and because of labor availability (the veterinary technicians needed to be present at all dip tanks and could not devote more than an hour per location). The eligibility criteria for livestock owners were those who: 1. owned cattle between October 2006 and September 2007; 2. attended a dip tank on a day when interviews were taking place; and 3. regularly accompany their cattle during grazing. Interviews were conducted with the first three livestock owners who agreed to participate on the day of interview.

Field rangers in the KNP are assigned to patrol specific regions of the perimeter fence at least once a week and record incidents in a geo-referenced database (Fadyen, 2005). All eligible field rangers in the 11 sections closest to the western fence of KNP and in the one private and 
one provincial reserve, were included in the study. The eligibility criteria for field rangers were those who: 1. worked in one or more of the 11 sections between October 2006 and September 2007; and 2. did not act as a translator for the project.

\subsection{Questionnaire development and administration}

Contacts between domestic livestock and wildlife were estimated by administering questionnaires to livestock owners and field rangers. The questionnaire for livestock owners included sections focused on demographics, wildlife/livestock contacts, and economic information. The contact section included questions on the number and frequency of contacts, group size, and type of wildlife species contacting livestock during October 2006 - March 2007 and April - September 2007. Contact was defined as 'wildlife and cattle visible together in an area equivalent to a football field (approximately 90-120 meters long and 45-90 meters wide)'. Only the data on wildlife-cattle contacts are presented in the current publication.

The questionnaire for field rangers included sections focused on demographics, wildlife/domestic livestock contact and wildlife and domestic livestock movement through the fence. The contact section consisted of questions on the frequency, group size and species of wildlife in contact with domestic livestock during October 2006 - March 2007 and April September 2007. The animal movement section consisted of questions concerning the frequency and type of wildlife escaping the park and the frequency and type of domestic livestock entering the park during the two time periods. Due to the small numbers of contacts reported between wildlife and other species of livestock (sheep, goats, and swine), only data collected on wildlife/cattle contact are presented in this publication. However, information on movement through the fence for multiple species of wildlife and both cattle and goats are presented here. 
Administered questionnaires were approved by the University of Pretoria, South African National Parks and the Institutional Review Board at Texas A\&M University. The questionnaires were reviewed by 18 people, including collaborators at the University of Pretoria and 8 state veterinarians in South Africa (at the 2007 Southern African Society for Veterinary Epidemiology and Preventative Medicine conference in Durban) prior to use. Veterinary technicians working in Limpopo province were trained to administer the questionnaire to livestock owners. The training session was organized by the Limpopo Department of Agriculture in Malamulele, RSA. The session lasted 2.5 hours, consisting of a discussion (0.5 hours) of the importance of the study, voluntary participation and confidentiality of the information and role playing ( 2 hours), in which a veterinary technician acted as a livestock owner and another technician acted as the interviewer. The importance of the questionnaire being quantitative (the number of contacts observed during a time period rather than yes/no), how to systematically read the questions and how and when to probe an interviewee for more information were discussed. A pilot study for field rangers was conducted in Phalaborwa to determine cultural context and identify any potential difficulty in understanding. Prior to administration, questionnaires were sent to all 13 section rangers so that they could discuss and help clarify questions with the rangers they supervised.

Participation was voluntary and a unique questionnaire identification number was used to protect participant privacy. The questionnaires were written in English and translated to the appropriate languages with the help of veterinary technicians and field rangers in the KNPI. The interview-based questionnaires were administered to livestock owners during November 2007, with interviews conducted at the dip tanks by veterinary technicians. The interview-based 
questionnaires were administered by the first author to field rangers in November and December 2007 with the help of a local translator.

\subsection{Statistical Analysis}

A descriptive analysis of the frequency, group size (median, minimum and maximum) and type of wildlife species seen in contact with livestock was conducted. Responses from livestock owners and field rangers reporting observed contacts between cattle and certain wildlife species (buffalo, impala, elephant, and warthog) during October 2006 - March 2007 were compared to livestock owners and field rangers reporting observed contacts during April September 2007 using McNemar's chi-square test. Field rangers reporting wildlife-livestock contacts inside KNP versus outside KNP were also compared using McNemar's chi-square tests with a type I error of 0.05 .

\section{Results}

\subsection{Descriptive results}

There were 7 veterinary technicians from three municipalities (Thulamela, Greater Giyani and Ba-Phalaborwa) in the buffer zone with vaccination of Limpopo province, who interviewed 87 livestock owners from 31 dip tanks. Three livestock owners were interviewed per dip tank, with the exception of Ba-Pahalaborwa, at which only 15 livestock owners could be enrolled at the 7 municipal dip tanks due to time and logistical constraints. Fifteen livestock owners (17\%) reported contacts between cattle and wildlife during October 2006 - September 2007. Contacts were reported in the following municipalities: Greater Giyani (13), Thulamela (1) and Ba-Phalaborwa (1). The total contacts between cattle and wildlife reported by the livestock 
owners (October 2006 - September 2007) were cattle-buffalo (16), cattle-impala (14), cattle-elephant (4) and cattle-warthog (1) (Figure 1).

Of the approximately 160 field rangers assigned to the 11 sections along the western boundary of the KNP and the one private and one provincial reserve, fifty-seven field rangers were interviewed for this study. Eighteen rangers (32\%) reported contacts between cattle and wildlife in the KNPI during October 2006 - September 2007. Field rangers reporting contacts were located in the following sections (from north to south) of the KNPI: Pafuri (5), Punda Maria (2), Shangoni (3), Mahlangeni (2), Sabi Sands private reserve (1), Manyeleti provincial park (1), Skukuza (2), Stolsnek (1), and Crocodile Bridge (1). The total contacts (October 2006 - September 2007) are shown in Figure 2.

\subsection{Differences in contacts between wildlife and cattle by time period}

Contacts between cattle and wildlife (buffalo, impala, elephant and warthog) reported by livestock owners in the KNPI were significantly higher during October 2006 - March 2007 compared to April - September $2007(\mathrm{p}=0.012)$. Contacts reported between cattle and the wildlife species noted above, with buffalo excluded, were also significantly higher during October - March compared to April - September $(\mathrm{p}=0.002)$ (Table 1). None of the wildlife species-specific reported contacts with cattle were significantly different by time period.

For field rangers, there was no significant difference in wildlife-livestock contacts during October 2006 - March 2007 and April - September 2007 in the KNPI (Table 2). Also there was no difference in contacts reported inside KNP compared to outside the KNP during this period (Table 3). Buffalo leaving the KNP without reported contacts with cattle was descriptively higher during October - March than during April - September, $(\mathrm{p}=0.077)$ (Table 4). 


\section{Discussion}

In this investigation, contacts between wildlife and cattle were reported by both field rangers and livestock owners. Contacts between these various species most likely occur due to congregation of animals around higher quality pastureland and water sources. A greater proportion (32\%) of field rangers reported contact between cattle and wildlife than livestock owners (17\%). An explanation could be that part of the field ranger's job is to conduct daily surveillance of the KNPI, whereas a livestock owner's motivation is to seek suitable grazing for their livestock, which they may then leave to graze unattended. In addition, this study relies on the abilities of livestock owners and field rangers to recall seeing interactions between wildlife and livestock. Field rangers might potentially be more likely to recall such interactions because this is part of their daily surveillance activities. The most common species-specific contact reported by both livestock owners and field rangers was cattle and buffalo, followed by cattle and impala. Contact between cattle and buffalo and cattle and impala are believed to be important for the transmission of FMD (Thomson, 1994; Keet et al., 1996; Vosloo et al., 2006) and tuberculosis (Michel et al., 2006) in the RSA.

A greater proportion of livestock owners reported contact between cattle and all wildlife species during October 2006 - March 2007 compared to April - September 2007. Contacts with elephant and warthog were only seen during October - March, inflating the overall proportions of contacts during that period. However, contacts with livestock were not significantly different for buffalo and impala, the species implicated in the transmission of FMDV to domestic livestock. There was no difference in wildlife-livestock contacts reported by field rangers during October - March and April - September. Field rangers reported contacts inside the KNP and 
also on the other side of the fence, outside the KNP, when they patrolled the fence. There was no significant difference in contacts reported inside the KNP compared to outside the KNP. This is an important finding because it indicates that contacts between cattle and wildlife are not unidirectional: once the fence is comprised the animals can pass into each other's territory without a preference for being inside or outside the park. Livestock are not permitted to be present in, or to graze in, the KNP. Results of our study suggest that once the fence is compromised it is possible for wildlife to leave and domestic livestock to enter the park.

There was no significant difference in domestic animals (cattle and goats) entering the park or wildlife leaving the park during the two study periods (Table 3), although reported contacts were higher in October 2006 - March 2007 compared to April - September 2007. Again this highlights the finding that both wildlife and domestic livestock probably move inside and outside the park irrespective of time of year.

The veterinary services and other governmental agencies in the study area play an important role in preventing diseases in wildlife and domestic livestock. One of the biggest challenges in the KNPI is monitoring, collecting, storing and sharing data on an accessible and standardized platform. Currently, field rangers monitor and record animal movements and compromises in the perimeter fence around the KNPI. Veterinary technicians are responsible for monitoring infectious disease in livestock, and wildlife that escape the park are managed by veterinary services in the KNP and adjacent provinces. There is a need for a systematic and standard approach to collecting information for livestock and wildlife to further understand the transmission of diseases between domestic livestock and wildlife. 


\section{Conclusion}

There was a difference in contacts between cattle and wildlife in the study area during October 2006 - March 2007 versus April - September 2007. Contact data collected in this study can be used to better understand the transmission of FMDV in the KNPI.

\section{Acknowledgements}

This work was partially funded by Texas A\&M University Foreign Animal Disease Defense Center through Dr. Gale Wagner. Veterinarians and veterinary technicians within the Limpopo Department of Agriculture are thanked for assisting with administering the questionnaires. The section managers in the Kruger National Park are thanked for providing translators to communicate the questionnaires. 


\section{References}

Bastos, A.D., Boshoff, C.I., Keet, D.F., Bengis, R.G., Thomson, G.R., 2000. Natural transmission of foot-and-mouth disease virus between African buffalo (Syncerus caffer) and impala (Aepyceros melampus) in the Kruger National Park, South Africa. Epidemiol Infect 124, 591-598.

Condy, J.B., Hedger, R.S., Hamblin, C., Barnett, I.T., 1985. The duration of the foot-and-mouth disease virus carrier state in African buffalo (i) in the individual animal and (ii) in a freeliving herd. Comp Immunol Microbiol Infect Dis 8, 259-265.

EMPRES, 1997. Prevention and control of transboundary animal diseases. Food and Agriculture Organization of the United Nations Rome.

Fadyen, S.C., 2005. Electronic Ranger Diaries. The Kruger National Park CyberTracker Program. In: CyberTracker (Ed.), Dicussion Papers.

Hargreaves, S.K., Foggin, C.M., Anderson, E.C., Bastos, A.D., Thomson, G.R., Ferris, N.P., Knowles, N.J., 2004. An investigation into the source and spread of foot and mouth disease virus from a wildlife conservancy in Zimbabwe. Rev Sci Tech 23, 783-790.

Hedger, R.S., 1972. Foot-and-mouth disease and the African buffalo (Syncerus caffer). J Comp Pathol 82, 19-28.

Keet, D.F., Hunter, P., Bengis, R.G., Bastos, A., Thomson, G.R., 1996. The 1992 foot-andmouth disease epizootic in the Kruger National Park. J S Afr Vet Assoc 67, 83-87.

Michel, A.L., Bengis, R.G., Keet, D.F., Hofmeyr, M., Klerk, L.M., Cross, P.C., Jolles, A.E., Cooper, D., Whyte, I.J., Buss, P., Godfroid, J., 2006. Wildlife tuberculosis in South African conservation areas: implications and challenges. Vet Microbiol 112, 91-100.

OIE, 1992-2006. Weekly disease information.

Thomson, G.R., 1994. Foot and Mouth Disease. In: Coetzer, J.A.W., G.R. Thomson, R.C. Tustin, N.P.J. Kriek (Ed.), Infectious diseases of livestock with special reference to southern Africa. Oxford University Press, Cape Town, pp. 825-952.

Thomson, G.R., Vosloo, W., Bastos, A.D., 2003. Foot and mouth disease in wildlife. Virus Res 91, 145-161.

Thomson, G.R., Vosloo, W., Esterhuysen, J.J., Bengis, R.G., 1992. Maintenance of foot and mouth disease viruses in buffalo (Syncerus caffer Sparrman, 1779) in southern Africa. Rev Sci Tech 11, 1097-1107.

Vosloo, W., Bastos, A.D., Boshoff, C.I., 2006. Retrospective genetic analysis of SAT-1 type foot-and-mouth disease outbreaks in southern Africa. Arch Virol 151, 285-298.

Vosloo, W., Boshoff, K., Dwarka, R., Bastos, A., 2002. The possible role that buffalo played in the recent outbreaks of foot-and-mouth disease in South Africa. Ann N Y Acad Sci 969, 187-190.

Vosloo, W., Thompson, P.N., Botha, B., Bengis, R.G., Thomson, G.R., 2009. Longitudinal Study to Investigate the Role of Impala (Aepyceros melampus) in Foot-and-Mouth Disease Maintenance in the Kruger National Park, South Africa. Transbound. Emerg. Dis. 56, 18-30. 
Table 1. Mean and median numbers of contacts reported by livestock owners $(n=87)$ between cattle and wildlife and the proportion of livestock owners reporting contacts in the Limpopo province of the Republic of South Africa in October 2006-March 2007 and April 2007September 2007.

\begin{tabular}{|c|c|c|c|c|c|}
\hline \multirow[b]{3}{*}{ Animals involved } & \multirow{2}{*}{\multicolumn{2}{|c|}{$\begin{array}{c}\text { Reported contacts } \\
\text { Oct. } 2006 \text { - March } 2007\end{array}$}} & \multirow{2}{*}{\multicolumn{2}{|c|}{$\begin{array}{l}\text { Reported contacts } \\
\text { April } 2007 \text { - Sept. } 2007\end{array}$}} & \multirow[b]{3}{*}{ P value* } \\
\hline & & & & & \\
\hline & $\begin{array}{l}\text { Mean, median } \\
\text { (min, max) }\end{array}$ & $\begin{array}{c}\text { No. } \\
\text { reporting } \\
\text { contact }(\%)\end{array}$ & $\begin{array}{l}\text { Mean, median } \\
\text { (min, max) }\end{array}$ & $\begin{array}{c}\text { No. } \\
\text { reporting } \\
\text { contact }(\%)\end{array}$ & \\
\hline All wildlife ${ }^{\dagger}-$ cattle $^{2}$ & $0.280,0(0,3)$ & $14(16)$ & $0.130,0(0,3)$ & $5(6)$ & 0.012 \\
\hline Other wildlife ${ }^{\ddagger}$ - cattle & $0.276,0(0,3)$ & $14(16)$ & $0.046,0(0,2)$ & $2(2)$ & 0.002 \\
\hline Buffalo - cattle & $0.100,0(0,3)$ & $7(8)$ & $0.080,0(0,3)$ & $3(3)$ & 0.219 \\
\hline Impala - cattle & $0.110,0(0,2)$ & $7(8)$ & $0.050,0(0,2)$ & $2(2)$ & 0.125 \\
\hline \multicolumn{6}{|c|}{ *Based on McNemar's chi-square tests comparing reported contacts for October 2006 - March } \\
\hline \multicolumn{6}{|c|}{2007 and April - September 2007.} \\
\hline
\end{tabular}


Table 2. Mean and median numbers of contacts reported by field rangers $(n=57)$ between cattle and wildlife and the proportion of field rangers reporting contacts in the Kruger National Park (KNP) of the Republic of South Africa in October 2006-March 2007 and April 2007-September 2007.

Reported contacts

Oct. 2006 - March 2007

Animals involved

\begin{tabular}{cc}
\hline Mean, median & No. \\
(min, max) & reporting \\
& contact $(\%)$
\end{tabular}

\section{Reported contacts}

April 2007 - Sept. 2007

No.

Mean, median

(min, max)

reporting $\mathbf{P}$ value*

$\operatorname{contact}(\%)$

\begin{tabular}{lccccc}
\hline All wildlife $^{\dagger}-$ cattle & $0.211,0(0,2)$ & $9(16)$ & $0.491,0(0,18)$ & $4(7)$ & 0.182 \\
Other wildlife ${ }^{\ddagger}$ cattle & $0.035,0(0,1)$ & $2(4)$ & $0.105,0(0,3)$ & $3(5)$ & 1.0 \\
Buffalo - cattle & $0.175,0(0,2)$ & $8(14)$ & $0.386,0(0,18)$ & $3(5)$ & 0.130 \\
Impala - cattle & 0 & $0(0)$ & $0.070,0(0,3)$ & $2(4)$ & 0.480 \\
\hline
\end{tabular}

*Based on McNemar's chi-square tests comparing reported contacts for October 2006 - March 2007 and April - September 2007.

$†$ All wildlife species include buffalo, impala, elephant and warthog.

†Other wildlife species include impala, elephant and warthog. 
Table 3. Mean and median numbers of contacts reported by field rangers $(n=57)$ between cattle and wildlife and the proportion of field rangers reporting contacts inside and outside the Kruger National Park (KNP) of the Republic of South Africa in October 2006-March 2007 and April 2007-September 2007.

\begin{tabular}{|c|c|c|c|c|c|}
\hline \multirow[b]{2}{*}{ Animals involved } & \multicolumn{2}{|c|}{ Inside the KNP } & \multicolumn{2}{|c|}{ Outside the KNP } & \multirow[b]{2}{*}{ P value* } \\
\hline & $\begin{array}{c}\text { Mean, median } \\
\text { (min, max) }\end{array}$ & $\begin{array}{c}\text { No. } \\
\text { reporting } \\
\text { contact }(\%)\end{array}$ & $\begin{array}{l}\text { Mean, median } \\
\text { (min, max) }\end{array}$ & $\begin{array}{c}\text { No. } \\
\text { reporting } \\
\text { contact }(\%)\end{array}$ & \\
\hline All wildlife ${ }^{\dagger}-$ cattle & $0.684,0(0,21)$ & $10(18)$ & $0.702,0(0,9)$ & $12(21)$ & 0.754 \\
\hline Buffalo - cattle & $0.561,0(0,19)$ & $9(16)$ & $0.158,0(0,2)$ & $6(10)$ & 0.508 \\
\hline Impala - cattle & $0.070,0(0,3)$ & $2(4)$ & $0.158,0(0,2)$ & $2(4)$ & 1.0 \\
\hline
\end{tabular}

*Based on McNemar's chi-square tests comparing reported contacts inside and outside the KNP. $†$ All wildlife species include buffalo, impala, elephant and warthog. 
Table 4. Mean and median numbers of domestic livestock observed entering the Kruger National Park (KNP) and wildlife observed leaving the KNP by field rangers $(n=57)$ and the proportion of field rangers reporting species movement into or out of KNP in October 2006-March 2007 and April 2007-September 2007.

\begin{tabular}{|c|c|c|c|c|c|}
\hline \multirow[b]{2}{*}{ Animals involved } & \multicolumn{2}{|c|}{$\begin{array}{c}\text { Entering/Leaving the KNP } \\
\text { Oct. } 2006 \text { - March } 2007\end{array}$} & \multicolumn{2}{|c|}{$\begin{array}{l}\text { Entering/Leaving the KNP } \\
\text { April } 2007 \text { - Sept. } 2007\end{array}$} & \multirow[b]{2}{*}{ P value* } \\
\hline & $\begin{array}{l}\text { Mean, median } \\
\text { (min, max) }\end{array}$ & $\begin{array}{c}\text { No. } \\
\text { reporting } \\
(\%)\end{array}$ & $\begin{array}{l}\text { Mean, median } \\
(\text { min, max })\end{array}$ & $\begin{array}{c}\text { No. } \\
\text { reporting } \\
(\%)\end{array}$ & \\
\hline Cattle & $1.320,0(0,24)$ & $16(28)$ & $1.420,0(0,24)$ & $12(21)$ & 0.424 \\
\hline Goat & $0.230,0(0,6)$ & $6(11)$ & $0.540,0(0,24)$ & $3(5)$ & 0.453 \\
\hline All wildlife ${ }^{\dagger}$ & $13.63,4(0,147)$ & $40(70)$ & $9.684,2(0,132)$ & $38(67)$ & 0.804 \\
\hline Other wildlife & $12.05,2(0,144)$ & $39(68)$ & $8.439,2(0,108)$ & $35(61)$ & 0.424 \\
\hline Buffalo & $1.580,1(0,20)$ & $30(53)$ & $0.540,0(0,24)$ & $22(39)$ & 0.077 \\
\hline Impala & $2.020,0(0,24)$ & $20(35)$ & $1.950,0(0,24)$ & $16(28)$ & 0.289 \\
\hline
\end{tabular}

*Based on McNemar's chi-square tests comparing sightings in October 2006 - March 2007 and April - September 2007.

$\dagger$ All wildlife species include buffalo, impala, elephant and warthog.

†Other wildlife species include impala, elephant and warthog. 


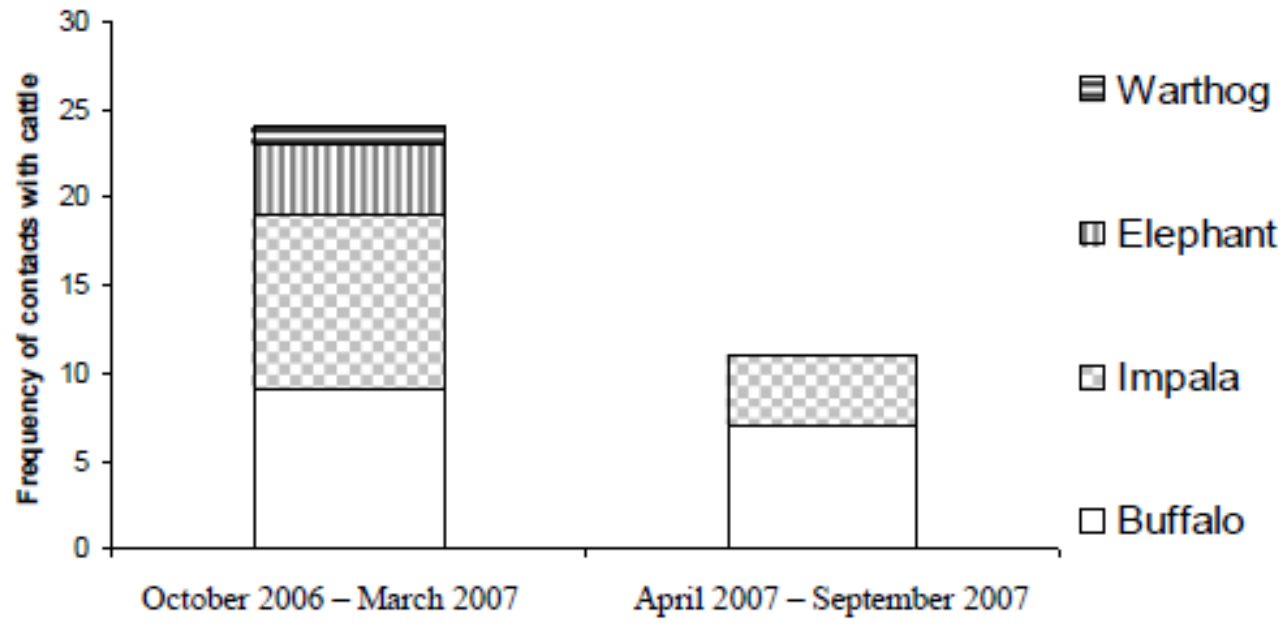

Figure 1: Frequency of contacts between wildlife and cattle reported by 87 livestock owners from October 2006 to September 2007 in the buffer with vaccination zone of the Limpopo province of the Republic of South Africa. 


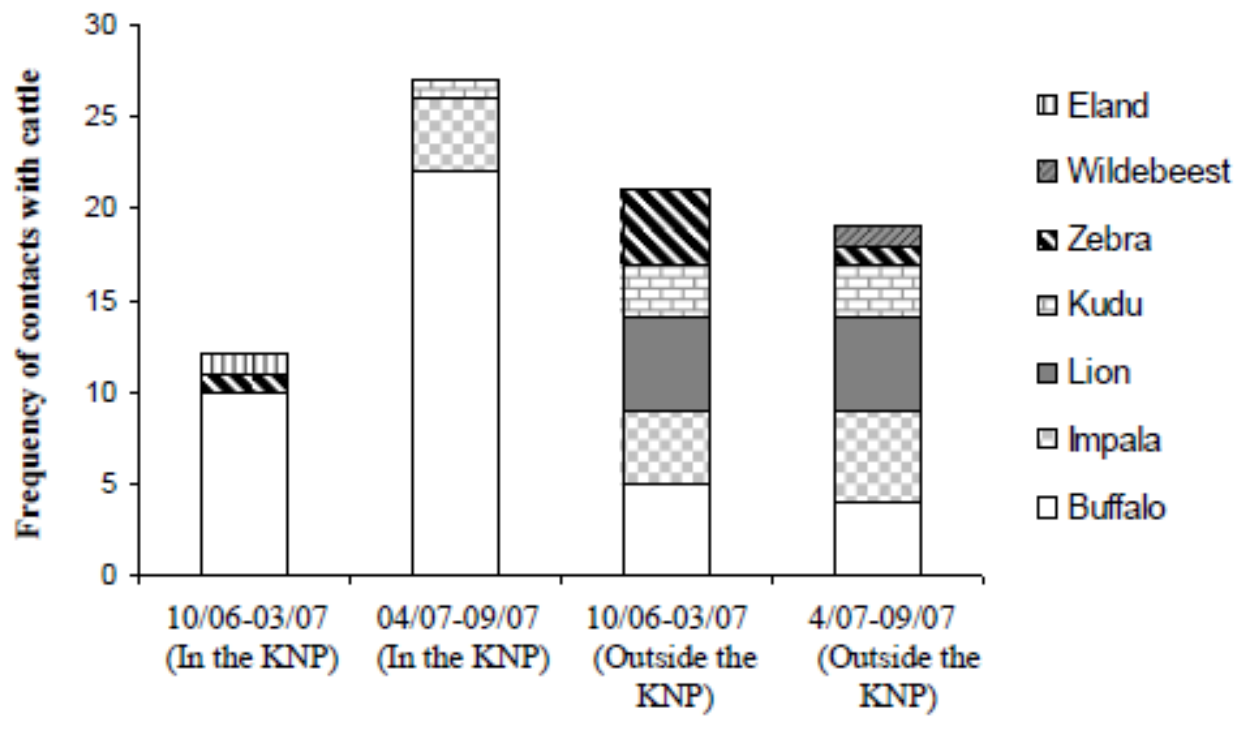

Figure 2: Frequency of contacts between wildlife and cattle reported by 57 field rangers from October 2006 to September 2007 inside and outside the Kruger National Park (KNP). 